\title{
Household Solid Waste Generation Rate and Onsite Handling Practices in Debre Berhan Town, Ethiopia
}

\author{
Asmamaw Abera Kebede ${ }^{1, ~ *, ~ T a d e s s e ~ L e l a g o ~ E r m o l o ², ~ T a k e l e ~ G e z a h e g n ~ D e m i e ~}{ }^{1}$, \\ Tufa Kolola Huluka ${ }^{1}$, Wendwesen Dibekulu Tsega ${ }^{1}$ \\ ${ }^{1}$ Department of Public Health, Medicine and Health Science Institute, Debre Berhan University, Debre Berhan, Ethiopia \\ ${ }^{2}$ Department of Nursing, Health Science College, Wachemo University, Hossana, Ethiopia
}

Email address:

asmenst13@gmail.com (A. A. Kebede), lelagotedasse@gmail.com (T. L. Ermolo), takele.gez44@gmail.com (T. G. Demie), tufabest@gmail.com (T. K. Hulaka), getwende@gmail.com (W. D. Tsega)

${ }^{*}$ Corresponding author

\section{To cite this article:}

Asmamaw Abera Kebede, Tadesse Lelago Ermolo, Takele Gezahegn Demie, Tufa Kolola Huluka, Wendwesen Dibekulu Tsega. Household Solid Waste Generation Rate and Onsite Handling Practices in Debre Berhan Town, Ethiopia. Science Journal of Public Health.

Vol. 5, No. 1, 2017, pp. 31-34. doi: 10.11648/j.sjph.20170501.14

Received: November 10, 2016; Accepted: November 26, 2016; Published: January 7, 2017

\begin{abstract}
Solid waste management is one of the public health problems in Ethiopia. Accurate and reliable information on solid waste generation rate and onsite handling practice are very important elements to plan and implement solid waste management system. This study aimed to assess solid waste generation rate and onsite handling practices among the households of Debre Berhan town. A community based cross-sectional study was conducted on 211 households, and systematic sampling technique was used to select those households. Data was collected through face to face interview using pre-tested and structured questionnaire for onsite handling practices. The amount of solid waste generated per day was weighed to determine generation rate. Data entry and cleaning were done using Epi Info version 3.5.4, and analyzed by SPSS version 20. Solid waste generation rate from the households of Debre Berhan town was $0.253 \mathrm{Kg} /$ capita/day. Majority of the households (85.8\%) in our study area had onsite storage, but only $8.5 \%$ of them had practiced appropriate onsite handling. Solid waste handling at household level was mainly the responsibility of the women (72\%) compared with others family members. Poor onsite solid waste segregation was observed from the present study as $90 \%$ of households store all types of wastes in a single container. In conclusion, onsite solid waste handling practice was poor in our study area with less shared responsibility among the family members.
\end{abstract}

Keywords: Solid Waste, Solid Waste Generation Rate, Onsite Handling

\section{Introduction}

Solid waste management is one of the major environmental burdens particularly in developing countries. An alarming rate of solid waste generation trends can be seen parallel to urbanization, industrialization and economic development. The environmental burden continues to be a major pressing issue threatening the environment and health of the people. The problems that related to solid waste intensified with the gradual increase in waste generation and its poor management. Accurate information on waste generation is necessary to monitor existing management systems and to make regulatory, financial and institutional decisions [1-5].

In most developing countries, average solid waste generation rate is exceeding one kilogram per capita per day. Solid waste generation rate varies depending on socioeconomic groups, family size and technological advances [2, 6-10]. Solid waste management processes start at sources of the wastes. Proper waste handling at household level has positive implication on waste management and public health. Onsite solid waste handling practices depend on the type of waste generated and public attitude. Appropriate onsite handling practice makes waste management easy and simple. 
Segregation is an essential component of onsite solid waste management practice. In several developing countries, mothers and daughters are mainly responsible for onsite waste handling [2, 11-13].

Some studies from developing countries have shown onsite solid waste handling practice was poor. Waste storage containers were not covered at household's level [14-16]. Few studies have been done in other towns of Ethiopia [7, $15,17]$, but information on solid waste generation and onsite handling is scarce in Debre Berhan town. Thus, this study was designed to assess solid waste generation rate and on-site handling practices of Debre Berhan town which are very important for solid waste management.

\section{Method and Materials}

\subsection{Study Area and Period}

This study was conducted in Debre Berhan town during May 2015. Debre Berhan town is a capital of North Shoa Zone of Amhara national regional state, Ethiopia, which situated 130 kilometers to the North East of Addis Ababa. According to 2007 census, the town has 94,829 total populations, and 10,000 households. The town has a total of nine Kebeles. A Kebele is the lowest administrative unit in Ethiopia.

\subsection{Study Design and Sample}

A community based cross-sectional study was conducted among 211 households to assess solid waste generation rate and on-site solid waste handling practices. The sample size was determined using a single population formula considering waste generation rate which is $0.1 \mathrm{~kg} / \mathrm{capita} /$ day (15), a 95\% confidence level, 5\% margin of error and design effect of 1.5. From nine Kebeles of the town, three were selected by simple random sampling technique. Systematic sampling technique was used to select the households from the three randomly selected Kebeles.

\subsection{Data Collection}

Data regarding onsite solid waste handling practices were collected using structured questionnaire and observational check list. The questionnaire was pre-tested before actual data collection and the necessary modifications were made on some items of the questionnaire. Trained data collectors who are health professionals were collected the data through face to face interview.

Average solid waste generation rate of households was estimated using the data obtained from households for seven consecutive days. Accordingly, data on waste generation was collected per day from each selected households for the seven consecutive days. Each household was given a plastic bag labeled with the corresponding house number to store the solid waste generated per day. In the same way, another plastic bag with the same label was given for each household for the next day collection, and this process continued until last day of data collection. Every morning, collected wastes were brought to the strategically selected working site.
Finally, solid wastes were weighed and recorded by the researchers.

\subsection{Data Processing and Analysis}

Data entry and cleaning were done using Epi Info version 3.5 .4 , and analyzed by SPSS version 20. Per capita per day solid waste generation rate (PCPDSWGR) was calculated using the following formula:

$$
\text { PCPDSWGR }=\frac{\text { Total Solid waste generation with in } 7 \text { days }}{7 \text { days } \mathrm{x} \text { total family size of } 211 \text { survey households }}
$$

\subsection{Ethical Consideration}

The proposal of this study was approved by Ethical Review Committee of Debre Berhan University, Institute of Medicine and Health Sciences. Verbal consent was obtained from each study participants before interview. Moreover, no personal identifiers were used on data collection questionnaire and the data obtained from the study participants were kept confidentially.

\section{Results and Discussions}

\subsection{Socio Demographic Data}

A total of 211 households were enrolled in this study giving $100 \%$ response rate. The average family sizes of the selected households were 3.5. The average family size in our study area is comparable with the national figure, Ethiopia [18]. Over three-fourth (77\%) of the households had monthly income above 1000 in Ethiopian birr. Majority of the respondents $(73.9 \%)$ were females.

\subsection{Solid Waste Generation Rate}

Solid waste generation rate is the amount of waste join to waste stream from human activities. The amount of solid waste generated from households in our study area was 0.253 $\mathrm{Kg} /$ capita/day which is lower than what have been reported in previous studies done in Addis Ababa [19] and Nairobi [9]. The possible difference might be due to the fact that solid waste generation rate was estimated from all solid waste sources in the previous studies. Other study from Hosanna town, Ethiopia [7] reported comparable figure with the present study. This could be due to the similarity in economic level and similar source of solid waste used to estimate generation rate. The current study revealed that biodegradable solid wastes were primarily generated from the households in composition. In Addis Ababa, biodegradable solid wastes are the largest amount of the residual solid wastes generated per household. Paper, cardboard and plastics are significant by mass in the composition of waste generated following organic wastes. Glass and metals appear in negligible amounts because they are not discarded for disposal but are sold to recyclable material buyers [19]. Similarly in Gondar town, biodegradable solid wastes were largely generated from the households with generation rate of $0.21 \mathrm{~kg} /$ person/day [17]. 


\subsection{Onsite Solid Waste Handling}

Onsite solid waste handling refers to the activities related to the handling of solid wastes until the waste placed in the solid collection bin used for storage before collection. A proper waste handling at household level has positive implication on waste management. Overall, $85.8 \%$ households in Debre Berhan town had onsite waste storage container. Plastic bag was most widely used by households to store their solid waste at onsite, but about $39 \%$ of the waste storage containers were not covered during data collection. Study in Accra also illustrated that majority of the households store their waste in baskets and plastic bags [14]. Poor onsite solid waste segregation was observed from this study as $90 \%$ of households store all types of wastes in single container (Figure 1). Moreover, only $8.5 \%$ of households had practiced appropriate onsite handling. In contrary to our study, other studies described solid waste segregation at site of generation was relatively good $[10,12]$.

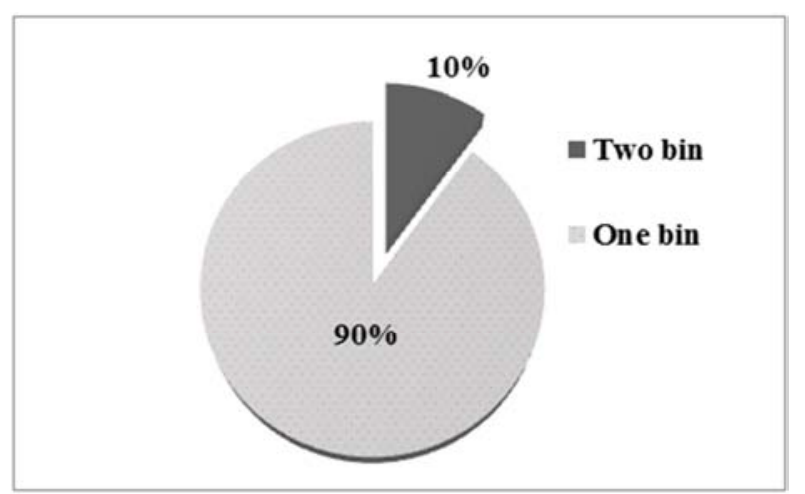

Figure 1. Number of solid waste collection bin for waste segregation at household level in Debre Berhan town, Amhara National Regional State, Ethiopia, May 2015.

Solid waste handling practices at household level was mainly the responsibility of women which account $72 \%$ compared with the responsibility of others family members. In other study, the involvement of male members of the family in solid waste management activities was also low at household level [12], but study in Cuba reported better active participation by household members [11].

\section{Conclusion}

Household solid waste generation rate of Debre Berhan town was $0.253 \mathrm{Kg} /$ capita/day in average. Biodegradable solid wastes were primarily generated from the households in composition. On-site solid waste handling practices were poor and overlooked as well. Thus, due attention should be given by family members of the households and the municipality to improve appropriate onsite solid waste handling practices.

\section{References}

[1] Borongan G and Okumura S. Municipal solid waste management report: statuesque and issues in southeast and East Asian countries 2010.
[2] United Nation Environmental Program (UNEP). Assessment of the solid waste management system of Bahir Dar town and the gaps identified for the development of an ISWM plan 2010 .

[3] Ulrich G C and Visvanatha M A. Solid waste management in least developed Asian countries. International conference on integrated solid waste management in Southeast Asian cities, Cambodia.

[4] Joseph A, et al. Environmental Engineering; solid waste management $5^{\text {th }}$ ed; Wiley JOHN WILEY and SONS, INC. USA $2003 ; 755-885$.

[5] Asian Productivity Organization (APO). Solid waste management: issues and challenges in Asia, survey on solidwaste management: overview of solid-waste management in Asian countries 2007: 3-7.

[6] United Nation Environmental Program (UNEP). Solid waste characterization and quantification of Bahir Dar city for the development of an Integrated Solid Waste Management (ISWM) plan 2010.

[7] Abiot A, et al. Household solid waste generation rate and physical composition analysis: case of Hossana city, SNNPRS, Ethiopia. J. Recent T rends Biosci 2012; 2(1): 2228.

[8] Ukwayi J k, Peter A and Inah S. An assessment of seasonal variation of waste generation and management in cross River state, Nigeria. Mediterranean Journal of Social Sciences 2012; $3(2)$.

[9] Muniafu M and Otiato E. Solid waste management in Nairobi, Kenya; A case for emerging economies. The Journal of Language, Technology \& Entrepreneurship in Africa 2010; 2(1).

[10] Abdus Salam M, et al. Generation and assessing the composition of household solid waste in commercial capital city of Bangladesh. Int. Journal of Environmental Science, Management and Engineering Research 2012; 1(4):160-171.

[11] Mosler J H, et al. Formulating waste management strategies based on waste management practices of households in Santiago de Cuba, Cuba; Habitat International 2006; 30: 849862.

[12] Regassa N, Sundaraa D and Bogale B. Challenges and opportunities in municipal solid waste management: the case of Addis Ababa city, Central Ethiopia. J Hum Ecology 2011; 33(3): 179-190.

[13] Tchobanoglous G and Kreith F. Handbook of solid waste management: solid waste stream characteristics $2^{\text {nd }}$ ed; McGraw-Hill companies, Inc, USA 2002; 131-160.

[14] Boadi K. Environmental and health impacts of household solid waste handling and disposal practices in $3^{\text {rd }}$ World cities: the case of the Accra metropolitan Area, Ghana; Journal of Environmental health 2005.

[15] Dereje D. Household solid waste generation rate, composition and content analysis for disposal and resource recovery in Hawassa town; Addis Ababa University school of graduate studies Environmental science program: master thesis 2009.

[16] Yimer S and O. P. Sahu. Assessment and Management of Municipal Solid wastes for Kombolcha City. World Journal of Soil, Water and Air Pollution 2014; 1(1): 1-20. Available from: http://www.wjswap.com 
[17] Gedefaw M. Assessing the current status of solid waste management of Gondar town, Ethiopia. International Journal of Scientific \& Technology Research 2015; 4 (9): 28-35.

[18] Central Statistical Agency [Ethiopia]. Ethiopia minidemographic and health survey Addis Ababa, Ethiopia 2014.
[19] Nicolas E. Solid waste management in Addis Ababa, Ethiopia; action brief residual household waste analysis 2013. Available from: www.futuregmegacities.org. 